\section{Artefacts in Sr isotope records}

SIR - High-resolution time-series analysis of single-species planktonic foraminifera from Indian Ocean Drilling Project (ODP) Site 758 resulted in the apparent resolution of 100,000 -year cyclicity in seawater ${ }^{87} \mathrm{Sr} /{ }^{86} \mathrm{Sr}$ which covaried with glacial-interglacial ice-volume fluctuations $\left(\delta^{18} \mathrm{O}\right)$ over the past 450,000 years ${ }^{1}$. Although the variability in ${ }^{87} \mathrm{Sr} /{ }^{86} \mathrm{Sr}$ was at, or near, analytical resolution at the $\pm 1 \sigma$ level, the persistence of the signal over several 100,000-year cycles, a strong in-phase covariation with global ice volume, and structure similar to that reported from Pacific core V28-238 (ref.
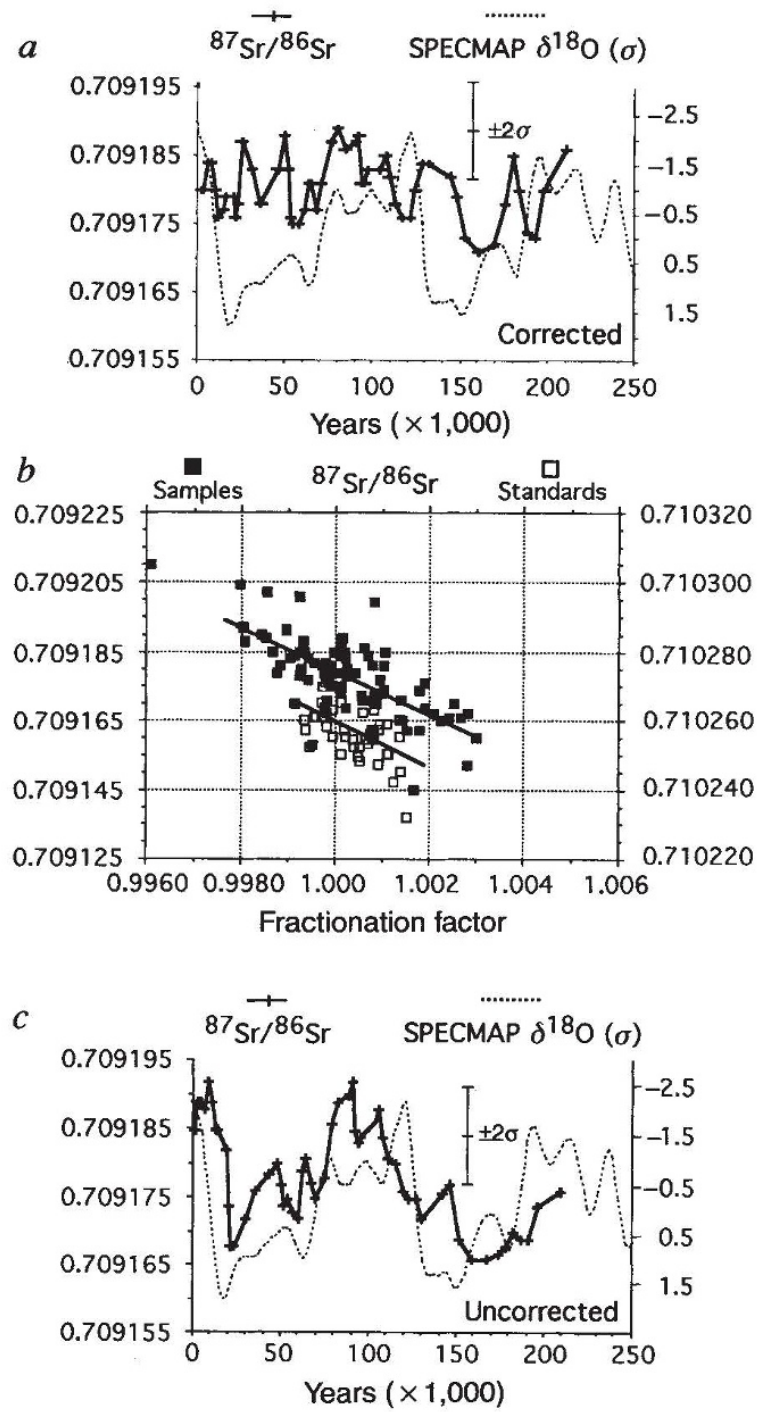

Seawater ${ }^{87} \mathrm{Sr} /{ }^{86} \mathrm{Sr}$ data from North Atlantic sediment core Chain 82-24. a, These high-precision data show no evidence of glacial-interglacial variability as depicted by the SPECMAP $\delta^{18} \mathrm{O}$ curve $^{8}$. $b$, Fractionation factor for samples and standards documenting positive relationship between high Sr-isotope values and increased fractionation (low values). $c$, Same data as in $a$ before correction for fractionation bias shown in $b$. The uncorrected data show 100,000-year glacial-interglacial variability. Data are plotted relative to an SRM-987 value of 0.710257 . Error bars are for Sr-isotope data. the glacial-interglacial signal observed in Site 758 is an analytical artefact related to fractionation bias. Nonetheless, the highprecision results presented above on the Chain data argue strongly against the existence of global changes in seawater ${ }^{87} \mathrm{Sr} /{ }^{86} \mathrm{Sr}$ (at the level of measurement precision) on glacial-interglacial timescales.

\section{Steven C. Clemens}

\section{Peter Gromet}

Department of Geological Sciences,

Box 1846, Brown University,

Providence,

Rhode Island 02912-1846, USA

John W. Farrell

Department of Oceanography,

University of British Columbia,

6270 University Blvd,

Vancouver V6T $1 Z 4$,

Canada

1. Clemens, S. C. et al. Nature 363, 607-610 (1993).

. Dia, A. N et al Nature 356, 786-788 (1992).

3. Clemens, S. C. et al. Min. Mag. 58A, 179-180 (1994)

4. Boyle, E. A. \& Keigwin, L. D. Earth planet. Sci. Lett. 76 135-150 (1985).

5. Henderson, G. M. et al. Min. Mag. 58A, 404-405 (1994).

6. Henderson, G. M. et al. Earth planet. Sci. Lett. (in the press).

7. Wasserburg, G. J. et al. Geochim. cosmochim. Acta 49 1875-1886 (1981)

8. Imbrie, J. et al. Milankovich and Climate, Pt 1 (eds Berger, A. L. et al.) 269-305 (Riedel, Hingham, 1984). pletely for fractionation effects. Without this additional correction, the Chain 82-24 record did show a 100,000 -year Sr-isotope signal and an in-phase relationship with ice-volume ( $c$ in the figure). Thus, an apparent (uncorrected) record of 100,000-year variability in the $\mathrm{Sr}$ isotope composition of sea water for this site is an analytical artefact that is apparently linked to environmental parameters that vary on glacial-interglacial timescales. Resolution of this linkage awaits further work, but does not detract from the conclusion that a glacial-interglacial $\mathrm{Sr}$ isotopic signal is not present in Chain 82-24. Similarly, high-precision attempts at replicating the V28-238 signal have also been unsuccessful ${ }^{5,6}$.

The observations of an analytical artefact affecting the Chain data caused us to carefully recheck our ODP Site 758 results for similar effects. These data were collected in static mode with an exponential fractionation correction ${ }^{7}$, and a fractionation bias could not be detected in the standards or samples of this dataset. Therefore we have no reason to suspect that

\section{Krill biomass in the Atlantic}

SIR - Acoustic target strength (TS) ${ }^{1}$ is an important parameter when using acoustic survey data to estimate the abundance of Antarctic krill (Euphausia superba Dana). Recently, when the TS of krill was reassessed ${ }^{2,3}$, it emerged that the previous values had been too high, leading to unrealistically low biomass estimates. Following the re-evaluation, it was recommended that new values ${ }^{3}$ should be used for the analysis of all acoustic survey data, including the re-analysis of important existing datasets ${ }^{3}$. Here, using recent krill TS values ${ }^{3}$, we report an estimate for the biomass of krill in the southwest Atlantic, one of the main spawning and feeding grounds of Antarctic krill.

As part of the international programme, the Biological Investigation of Marine Antarctic Systems and Stocks (BIOMASS), a large acoustic survey (first international BIOMASS Experiment FIBEX) was undertaken in selected regions of the Southern Ocean. The survey covered areas thought to include a high krill biomass, and the survey strategy assumed that areas not sampled were characterized by a low krill biomass ${ }^{4}$. Recent evidence from fisheries data suggests that most of the krill biomass in the southwest Atlantic region is within the geographical limits set for the FIBEX survey, with the highest concentrations of 